Review

\title{
Tumor and its microenvironment: A synergistic interplay
}

\author{
Veronica Catalano $^{\mathrm{a}, 1}$, Alice Turdo ${ }^{\mathrm{a}, 1}$, Simone Di Franco ${ }^{\mathrm{a}}$, \\ Francesco Dieli $^{\mathrm{b}}$, Matilde Todaro ${ }^{\mathrm{a}}$, Giorgio Stassi ${ }^{\mathrm{a}, *}$ \\ a University of Palermo, Department of Surgical and Oncological Sciences, Laboratory of Cellular and Molecular Pathophysiology, \\ Via Liborio Giuffrè, 5, 90127 Palermo, Italy \\ b University of Palermo, Biopathology and Biomedical Methodologies, Corso Tukory 211, 90134 Palermo, Italy
}

\section{A R T I C L E I N F O}

\section{Keywords:}

CSCs

Tumor microenvironment

ROS

Hypoxia

Angiogenesis

\begin{abstract}
A B S T R A C T
The mutual and interdependent interaction between tumor and its microenvironment is a crucial topic in cancer research. Recently, it was reported that targeting stromal events could improve efficacies of current therapeutics and prevent metastatic spreading. Tumor microenvironment is a "complex network" of different cell types, soluble factors, signaling molecules and extracellular matrix components, which orchestrate the fate of tumor progression. As by definition, cancer stem cells (CSCs) are proposed to be the unique cell type able to maintain tumor mass and survive outside the primary tumor at metastatic sites. Being exposed to environmental stressors, including reactive oxygen species (ROS), CSCs have developed a GSH-dependent antioxidant system to improve ROS defense capability and acquire a malignant phenotype. Nevertheless, tumor progression is dependent on extracellular matrix remodeling, fibroblasts and macrophages activation in response to oxidative stress, as well as epithelial mesenchymal transition (EMT)-inducing signals and endothelial and perivascular cells recruitment. Besides providing a survival advantage by inducing de novo angiogenesis, tumor-associated vessels contribute to successful dissemination by facilitating tumor cells entry into the circulatory system and driving the formation of pre-metastatic niche. In this review, we focus on the synergistic effect of hypoxia inducible factors (HIFs) and vascular endothelial growth factors (VEGFs) in the successful outgrowth of metastasis, integrating therefore many of the emerging models and theories in the field.
\end{abstract}

(c) 2013 Elsevier Ltd. All rights reserved.

\section{Introduction}

Colorectal cancer (CRC) is the third most commonly diagnosed cancer in the world and one of the major causes of death worldwide [1]. The prevention and the early diagnosis are surely the most important approaches for reducing the burden of CRC, given the symptoms of early disease occur just in $5 \%$ of cases. A significant portion of patients who receive surgery and adjuvant therapy still develop recurrences and metastasis and this phenomenon seems to be driven in some cell subsets by the acquisition of resistance to conventional therapy, such as chemo- and radio-therapy [2].

Growing evidence indicates that a cellular subpopulation with stem cell like features, commonly referred to as cancer stem cells (CSCs), is critical for tumor generation and maintenance.

Abbreviations: CSCs, cancer stem cells; CRC, colorectal cancer; EMT, epithelial mesenchymal transition; ECM, extracellular matrix; ROS, reactive oxygen species; MMPs, matrix metalloproteinase; CAFs, cancer-associated fibroblasts; CAMs, cancer-associated macrophages; GSH, reduced glutathione; HIF, hypoxiainducible factor; VEGF, vascular endothelial growth factor.

* Corresponding author. Tel.: +39 0916553211 ; fax: +390916553238.

E-mail address: giorgio.stassi@unipa.it (G. Stassi).

1 These authors contributed equally to this work.
A recent study showed that within the tumor population it is possible to identify a heterogeneous population of cells with different biological roles [3]. Recent advances in stem cell biology are revealing that this cellular fraction shares many properties with normal adult stem cells, including dormancy (quiescence), active DNA repair machinery, the expression of several ABC drugs transporters and an intrinsic resistance to apoptosis [4]. As their normal counterpart, the colon CSCs reside in a specialized microarchitectonic structures or niches that respond to both local and systemic conditions providing also protection against conventional therapies [5].

Moreover, microenvironmental stimuli, such as those involved in the epithelial-mesenchymal transition (EMT) and hypoxia, indirectly contribute to chemoresistance by inducing in cancer cells a stem like-phenotype. Understanding the driving force of tumor progression and the relationship between cancer cells and microenvironment could be fundamental in developing innovative therapeutic strategies for a better and definitive response on patient treatments.

\section{CRC, stem cell niche and colon CSCs}

It is widely accepted that CRC progression is driven by the acquisition of 4-5 progressive mutations in oncogenes or tumor 
suppressor genes [6]. Some driver mutations frequently occur in the same gene sequences and are shared by most of the people affected by this cancer, whereas some mutations are different and responsible of the final cancer phenotype in individual patients [7]. Most of the information about CRC derives from the study of familial adenomatous polyposis (FAP), an autosomal dominant colon cancer syndrome caused by APC gene mutation [8]. APC is involved in the regulation of Wnt pathway that, as we will discuss later in this review, can regulate cell proliferation, differentiation, migration and apoptosis [9]. Tumor progression is also achieved by other mutations such as KRAS, SMAD2/4, TP53 and deletion of chromosome $18 \mathrm{q}$ [10].

It was recently demonstrated that despite the great heterogeneity and biological diversity of CRC it is possible to distinguish three different subtypes. De Sousa et al. indeed showed that two of these subtypes have already been identified for chromosomal-instable and microsatellite-instable cancer. A third one, prognostically unfavorable, is characterized by microsatellite stability and relatively more $\mathrm{CpG}$ island methylator phenotype-positive, thus rendering it impossible to be identified on the basis of characteristic mutations [11].

The presence of a distinct population with stem cell characteristics among disseminated and circulating cancer cells may be of clinical relevance, not only for their putative role in metastasis formation and recurrence, but also for their role in resistance to conventional therapy. CSCs are likely to share many properties of normal stem cells as mentioned above, which may underlie their capacity to survive therapeutic protocols based on genotoxic agents targeting actively proliferating cells [12].

First invoked by Paget, the "seed and soil" hypothesis suggests that the successful growth of metastatic cells depends on the interactions and properties of cancer cells (seeds) and their potential target organs (soil). Additionally, new concepts include: (i) the role of cancer stem-like cells as putative cells of metastatic origin (the "seeds"); (ii) the mechanism of EMT in driving epithelial cell into the blood stream to avoid anoikis, or anchorage independent cell death; and (iii) the reverse process of EMT, or mesenchymal to epithelial transition (MET), which promotes conversion back to the parent cell morphology and growth of macrometastasis in the target organ, open a new broad of aspect on this issue [13].

The microenvironment plays a crucial role in maintaining the pluripotency of colon SCs at the base of colon crypts influenced by fibroblast, endothelium and inflammatory cells, cytokines and growth factors secreted by these cells (in particular HGF) thus finely regulating the balance between self-renewal and differentiation of the staminal population [14-16]. The most characterized pathway involved in the maintenance of colon stem cells is Wnt [17-19], and it is clearly highlighted by the different expression of Wnt members along the colon crypt [20], even if the maintaining of stemness and the differentiation pattern is actually the result of the fine collaboration with other important pathways, such as PTEN-PI3K-Akt [21,22], BMP [23], Notch [24] and Sonic hedgehog (Shh) [25].

\section{EMT, pre-metastatic niche and metastasis formation}

Metastasis formation is considered a complex multi-step process with sequential molecular and cellular events that permit transformed cells to gain access to the blood stream (intravasation), survive their journey through the blood stream, and ultimately traverse through the microvasculature of target organs (extravasation) to deposit, survive, and grow in a foreign tissue environment. The EMT represents the first step of this highly regulated cascade and it is an important biological process initially studied in normal tissues during the organogenesis and then extended in the pathogenesis of cancer diseases, particularly referred to the acquisition of migratory phenotype in CRC cells [26]. After extravasation from the circulation into the target organ, aberrant cells must implant, proliferate, and induce angiogenesis in order to survive and grow in a foreign and presumably "hostile" environment. These phenomena are driven not only by genetic and/or epigenetic alteration of cancer cells, but also by the non-neoplastic stromal cells [27].

The EMT is characterized by the loss of epithelial properties, including the apico-basal polarity and cell adhesion, the E-cadherin, occluding and cytokeratins expression, and at the same time the acquisition of N-cadherin, vimentin, fibronectin, Twist1, zincfinger proteins (SNAIL, SLUG, ZEB) and matrix metalloproteinases (MMPs) expression, all events that lead to an increased cell mobility [28]. Moreover, EMT-inducing factors released by the surrounding microenvironment [29] can affect the invasive phenotype in epithelial malignancies initiation. Key regulators of this process are TGF- $\beta$ (by the activation of Twist, SLUG and ZEB2), PI3K/Akt (increasing the mTOR kinase expression), Shh and Wnt [30,31].

Currently, dissemination and spread of cancer cells during the tumor progression are elective events underling the invasion through the tissue extracellular matrix (ECM). It was recently shown that tumor cells have two different modes of motility: (1) the acquisition of a mesenchymal phenotype, as previously described that identifies a mesenchymal motility mode and (2) the amoeboid migration [32]. The mesenchymal mode is characterized by the acquisition of an elongated morphology and activation of the small GTPase Rac [33]; the amoeboid motility is defined by a rounded or ellipsoid cell morphology and weak interactions with the surrounding matrix, driven by Rho expression, which induce membrane blebbing through Rho-associated protein kinase (ROCK)-dependent myosin II phosphorylation and consequent actomyosin contractility [34]. These two migration modes are interconvertible and regulated by microenvironmental influences. The possibility to switch from one mode to the other one highlights the cell plasticity that accomplishes movement from the primary tumor, establishment in an ectopic site, and survival therein [35].

The balance between high levels of activated Rac and Rho proteins regulates finely the motility mode. Moreover, Rac signaling inhibits amoeboid movement through its effector WASP-family verprolin-homologous protein 2 (WAVE2), and in the same way Rho/ROCK suppresses Rac by the activation of ARHGAP22, a GTPase-activating protein (GAP) [36].

Although RHO gene mutations are extremely rare, their altered expression has been assessed in many human cancers, including CRC. In particular, RhoA is frequently overexpressed and its induction is rapidly mediated by TGF- $\beta$ [37], while depletion of Rac1 strongly correlates with the inhibition of lamellipodia formation, cell migration and invasion in carcinoma cells [38].

Furthermore, recent study established the independent contribution of KRAS and BRAF mutations, which rarely coexist in human tumors, to migration and invasion of CRC cells through Rho GTPases signaling. Although KRAS and BRAF are common members of the same pathway, Makrodouli et al. showed that BRAF mutation enhances cell migration through RhoA activation, and its effect is more pronounced compared to KRAS. These findings are expected to eventually result in tailor-made therapies against Rho pathway components, since it depends on the genetic background of the cancer patient [39].

\section{Status redox and hypoxia: two sides of the same coin}

In the absence of an aberrant microenvironmental stimuli, genetic and epigenetic alterations in tumor cells are insufficient to induce primary tumor progression [27]. Either through structure and function-based mechanisms, including ECM remodeling, 
release of cytokines and growth factors, metabolic changes, or activation of stromal components, microenvironment enables tumor cells to achieve an aggressive phenotype [32].

As observed, reactive oxygen species (ROS) have emerged as an important factor affecting several cancer hallmarks. ROS are involved in the acquisition of self-sufficiency in proliferation signals by a ligand-independent receptor tyrosine kinase transactivation as well as loss of contact inhibition and anchorage-dependence cell growth. The development of a more aggressive phenotype is also promoted by ROS through MMPs secretion, EMT program activation, Met overexpression and regulation of cellular plasticity induced by the Rac1/RhoA antagonism [40,41]. Moreover, ROS sustain de novo angiogenesis by inducing the recruitment of perivascular cells and the activation of endothelial progenitors through the vascular endothelial growth factor (VEGF) and angiopoietin (Ang) release. Besides being involved in evading apoptosis by the activation of survival pathways, specifically PI3K/AKT, $\mathrm{NF}-\mathrm{kB}$, and anoikis resistance, ROS increase the sensibility to mutagenic agents and help escape from the immune surveillance system [42].

Oxidative stress can derive from either extrinsic or intrinsic source (Fig. 1). Cancer-associated-fibroblasts (CAFs) or macrophages (CAMs) synergize in the induction of a pro-oxidant environment. Due to the activation of Nitric Oxide Synthase 2 (NOX2), CAMs can directly produce ROS resulting in CAFs recruitment and MMPs activation [43]. Moreover, by secreting the master pro-inflammatory cytokine TNF $\alpha$, CAMs prime the NF-kB activation in both stromal and cancer cells, which in turn up-regulates SNAI1 expression [44]. In response to intrinsic and extrinsic oxidative stress, CAFs support tumor growth and promote EMT changes in cancer cells by secreting growth factors and ECM degrading proteases. Moreover, their production of extracellular matrix proteins promotes the recruitment of endothelial precursor cells from bone marrow [45]. Aging-induced oxidative stress concurs to transform fibroblasts into pro-inflammatory cells and induce an EMT program in the neighboring epithelial cells by secreting the so-called senescent activated secretory pathways (SASP) factors, which include pro-inflammatory cytokines and MMPs [46]. Klimova et al. demonstrated that hypoxia also improves ROS generation by deregulation of the mitochondrial complex III resulting in ROS release into the cytosol [47].

Interestingly, TGF $\beta$ has been correlated to redox control of EMT, either directly by the activation of MAPK or indirectly by ERKmediated Smad 2 phosphorylation. As shown by Rhyu et al., in renal tubular epithelial cells, TGF $\beta 1$ stimulation induces E-cadherin loss, $\alpha$-SMA and fibronectin up-regulation. These EMT-related molecular events are prevented by the inhibition of both NADPH oxidase (NOXes) and mitochondrial electron transfer chain subunit I, suggesting that NOXes and mitochondrial metabolism are important sources of TGF $\beta$-induced cellular ROS [48]. Similarly, Zhang et al. identified ferritin heavy chain (FHC) as a critical modulator of TGF $\beta$-induced EMT. By repressing the synthesis of FHC, a cellular iron storage protein, TGF $\beta$ promotes iron release and subsequent increase in the intracellular labile iron pool (LIP), which is associated with redox-mediated activation of p38MAPK. Thus, FHC overexpression abrogates TGF $\beta$-induced LIP increase resulting in ROS elimination and EMT suppression [49].

Cancer cells exacerbate the oxidant microenvironment by enhanced basal metabolic activity through aberrant growth factors and cytokines signaling as well as increased activity of ROSproducing enzymes, such as NOXes, cyclooxygenase (COXes) or lipoxygenases (LOXes) [50]. Moreover, high levels of ROS may result from down-regulation of Jun D, a transcriptional activator of FHC that is known to minimize LIP-dependent ROS generation [51].

To protect themselves from oxidative stress, cancer cells develop adaptation strategies, including increased expression of
Extrinsic oxidative stress

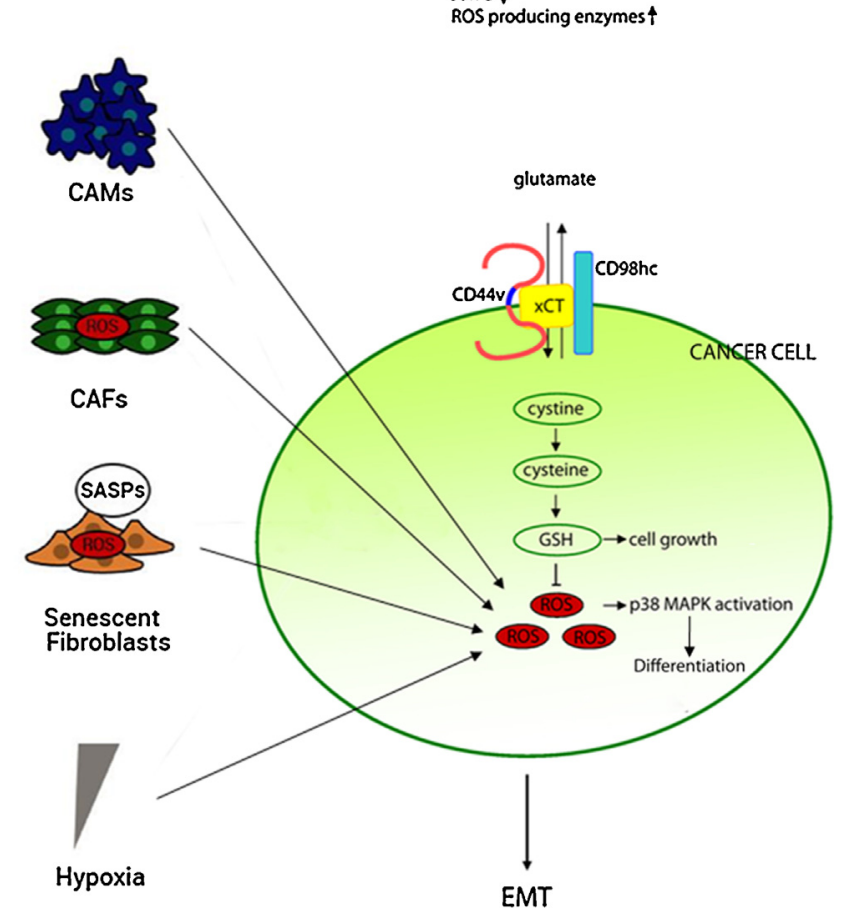

Fig. 1. Extrinsic and intrinsic production of oxidative stress. CAMs and hypoxia induce a pro-oxidant environment, mandatory for CAF activation and senescent fibroblasts conversion into pro-inflammatory cells, affecting in turn EMT of cancer cells. Due to Jun D downregulation and increased activity of ROS-producing enzymes, cancer cells exacerbate the production of oxygen radicals. CD44v stabilizes the subunit xCT at the plasma membrane by promoting GSH synthesis and tumor growth. Cancer-associated macrophages (CAMs), cancer-associated fibroblasts (CAFs), senescent activated secretory pathways (SASPs), reactive oxygen species (ROS), reduced glutathione (GSH), CD44 variant (CD44v), the light-chain subunit of cystine-glutamate antiporter system xc(-) (xCT), epithelial mesenchymal transition (EMT).

scavenger anti-oxidative enzymes and pro-survival molecules. Particularly, reduced glutathione (GSH) is the major intracellular antioxidant factor by reducing the ROS levels and suppressing ROS-dependent activation of p38MAPK. Ishimoto et al. demonstrated that in gastrointestinal cancer cells a CD44 variant (CD44v) maintains high levels of GSH by stabilizing the xCT expression at the plasma membrane. XCT is the light-chain subunit of cystine-glutamate antiporter system xc(-), which exchanges extracellular cystine uptake for intracellular glutamate, thereby promoting GSH synthesis (Fig. 1). At first, glutamate-cysteine ligase couples glutamate and cysteine to form $\gamma$-glutamylcysteine. Glutatione synthetase then catalyzes the formation of GSH from glycine and $\gamma$-glutamylcysteine. Since cysteine availability is a ratelimiting factor for GSH synthesis, CD44-mediated stabilization of $\mathrm{xCT}$ plays a key role in the GSH-dependent antioxidant system, promoting the proliferation of cancer cells and the formation of lethal gastrointestinal tumors. This is supported by the observation that CD44 depletion reduces the number of proliferating tumor progenitor cells and inhibits gastric tumor development in Gan (Gastric Neoplasia) mice through the ROS-dependent p38MAPK activation and $\mathrm{p} 21^{\mathrm{CIP} 1 / \mathrm{WAF} 1}$ upregulation. The antioxidant potential of gastric cancer cells confers resistance to ROS-inducing anticancer drugs, such as cisplatin and docetaxel. Consistently, in an HCT116 xenograft model, the specific xCT inhibitor sulfasalazine suppresses CD44-dependent tumor growth in parallel with the activation of p38MAPK, suggesting that the suppression of XCT by sulfasalazine might impair the ROS defense ability of CD44v-expressing CSCs and improve the efficacy of currently available treatments [52] (Fig. 2). 


\author{
(1) Primary Tumor \\ EMT: Snail, Twist \\ Glucose metabolism: LDHA, PDK1
}
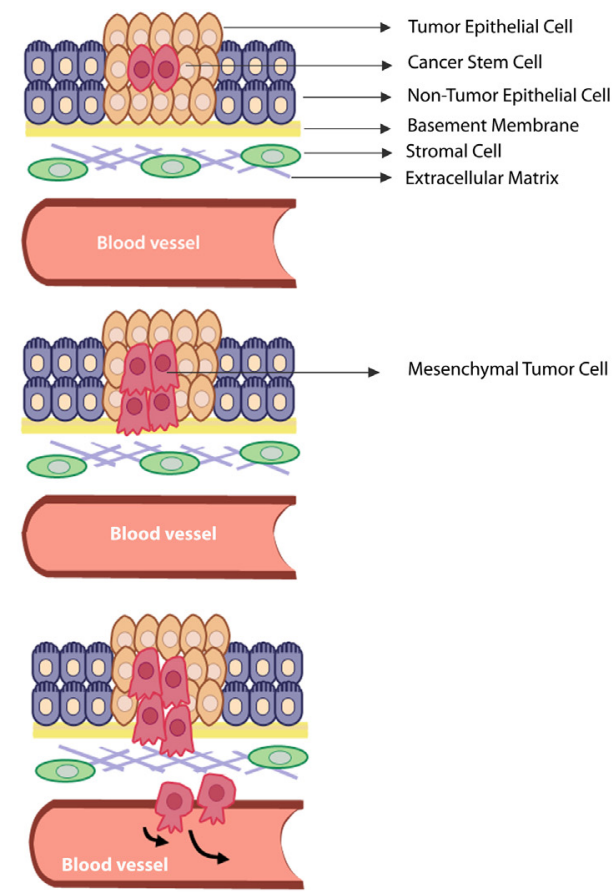

(2) Invasive Switch

Motility: LOX, AMF

Invasion: CTSP, MMP2

(3) Access to blood vessel: VEGF, MMPs, miR372, 373

(4) Exit from blood vessel: VEGF, MMPs, ANGPTL4

(5) Premetastatic niche: LOX
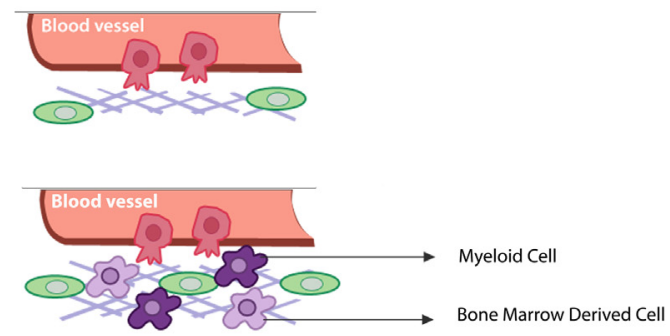

(6) Metastatic colonization: Homing: CXCR4, LOX Angiogenesis: VEGF

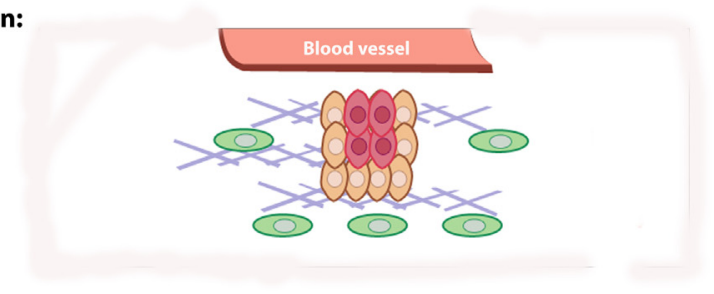

Fig. 2. Regulatory functions of hypoxia in different steps of metastasis. (1) During primary tumor growth, hypoxia acts as inductor of "glycolytic" phenotype and executor of EMT. (2) Under hypoxia, tumor cells gain an improvement in motility and invasion capacity, facilitating thereby detachment and dissemination from the primary site. (3 and 4 ) Increased expression of VEGF and MMPs induced by hypoxia is critical to penetrate the vasculature and promote the subsequent exit. (5) By the recruitment of bone marrowderived cells and $\mathrm{CD} 11 \mathrm{~b}^{+}$myeloid cells to secondary organs, LOX secreted by hypoxic tumor cells forms the premetastatic niche. (6) Hypoxia-dependent induction of CXCR4 and angiogenesis contribute to the successful metastatic colonization. Epithelial mesenchymal transition (EMT), lactate dehydrogenase A (LDHA), pyruvate dehydrogenase kinase 1 (PDK1), Lysyl oxidase (LOX), autocrine motility factor (AMF), cathepsin D (CTSD), matrix metalloproteinase (MMPs), vascular endothelial growth factor (VEGF), angiopoietin-like 4 (ANGPTL4).

CD44 and its variant isoforms have already been identified as tumor metastasis-associated proteins. Ectopic expression of CD44v6 splice variant confers metastatic potential to non metastatic tumor cell lines, promoting Met activation by its ligand HGF that is mainly secreted by mesenchymal cells [53]. The importance of the CD44v6 and Met multimeric signaling in cancer progression has been strengthened by the observation that adenoma growth in the $\mathrm{Apc}^{\mathrm{Min} /+}$ mice model was reduced by inhibiting the CD44v6 expression through short hairpin RNA/nanoparticles technology [54]. Moreover, Jung et al. showed that CD44v6 supports tumor cell migration and apoptosis resistance since only the matrix assembled by CD44v6-competent but not-deficient cells induces metastasis formation [55]. Given that disseminating cells are exposed to high levels of ROS during tumor progression, metastatic growth requires also adequate ROS defense ability to successfully colonize secondary sites. Interestingly, knockdown of the redox protein thioredoxin-like 2 has been reported to inhibit tumorigenesis and metastasis of human breast cancer cell lines upon transplantation into immunodeficient mice by enhancing ROS levels and reducing NF- $\kappa \mathrm{B}$ activity [56]. It has also been investigated the role of $\mathrm{CD} 44 \mathrm{v}-\mathrm{xCT}$ in lung metastasis. By promoting xCT-dependent GSH synthesis, CD44 expression allows mouse 4T1 breast cancer cells to evade high levels of ROS produced by neutrophils and colonize the lung. It is not surprising that knockdown of epithelial splicing regulatory protein 1 in CD $44^{+}$subpopulation induces an isoform switch from CD44v to $\mathrm{CD} 44 \mathrm{~s}$, resulting in reduced $\mathrm{xCT}$ expression and lung metastasis suppression [57]. 
Proliferating tumor cells distance themselves from the vasculature and colonize an environment deficient in oxygen and nutrients. Therefore, tumor cells need to reprogram their metabolism by increasing glycolytic activity and decreasing aerobic respiration rate. This shift is mediated by an increase in ROS levels generated by mitochondrial complex III, which accounts for hypoxia-inducible factor-1 (HIF-1) stabilization via oxidation/inactivation of prolyl hydroxylases and release from Von Hipper-Lindau (VHL)-mediated degradation. When stabilized in hypoxia, HIF- $1 \alpha$ dimerizes with HIF- $1 \beta$ and translocates into the nucleus. By interacting with the co-activators $\mathrm{CBP} / \mathrm{p} 300$, the $\alpha / \beta$ heterodimer HIF-1, bound to hypoxia-response elements (HREs) in target genes, mediates the expression of proteins involved in the formation of new vasculature and metabolic adaptation to hypoxia [58]. HIF-1 $\alpha$ increases the transcription of glucose transporters and glycolytic enzymes as well as lactate dehydrogenase A (LDHA) and pyruvate dehydrogenase kinase 1 (PDK1), resulting in the diversion of pyruvate toward lactate away from mitochondrial oxidative phosphorylation [59]. Additionally, mutations of tumor suppressor genes (PTEN, VHL) and oncogenic pathways (Ras/MAPK, PI3K-Akt) converge on HIF-1 $\alpha$ activation through an oxygen-independent mechanism [58]. Specifically, in CRC hypoxia activation of wild-type K-Ras mediates Akt phosphorylation and resistance to apoptosis [60].

Similar to HIF- $1 \alpha$, HIF- $2 \alpha$ is involved in the regulation of hypoxia tumor response. Interestingly, Heddleston et al. reported a role of HIF2 $\alpha$ in reprogramming non-stem cancer cells toward a stemlike phenotype by inducing the expression of key stem cell genes, like OCT4, NANOG and MYC. Concordantly, overexpression of HIF$2 \alpha$ in glioma non-stem cells increased neurospheres formation and tumorigenic capacity [61]. Moreover, as shown by Xue et al., HIF2 $\alpha$ activation modulates colon tumorigenesis in Apc Min/+ mice by overexpression of intestinal iron transport. The resulting iron intake contributes to dysregulation of local iron homeostasis, which in turn affects cancer progression through increasing cell survival and proliferation [62].

Hypoxia has been reported as an important driving force for the multistep process of metastasis. The early EMT-related events induced by hypoxia support ROS-dependent GSK-3 $\beta$ inactivation, followed by SNAIL nuclear translocation and E-cadherin loss $[63,64]$. In response to hypoxic conditions, Notch signaling up-regulates Snail expression by two distinct but synergistic mechanisms, involving both direct transcriptional activation of SNAI1 [65] and an indirect mechanism operating via the ECM protein lysyl oxidase (LOX) [66]. Moreover, Twist expression, directly induced by HIF- $1 \alpha$ through the HRE located in its promoter, contributes to cadherin profile changes with E-cadherin down-regulation followed by N-cadherin upregulation [64]. At a later stage, activation of $W n t / \beta$-catenin pathway and increased invasiveness are sustained by HIF- $1 \alpha$ - and VEGF-dependent events [63]. Particularly, hypoxia-induced invasion is associated with basement membrane degradation and ECM remodeling by upregulation of cathepsin D (CTSD) and MMP2 [58,67]. Hongo et al. proposed that the up-regulation of $\beta 1$ integrin expression by hypoxia in CRC cells increases the ability to adhere and migrate on collagen fibers [68].

The role of HIF- $1 \alpha$ in cell migration is related to improved LOX expression. In hypoxic cancer cells, LOX mediates the covalent cross-linking of collagen fibers and elastin, thereby increasing cell focal adhesion kinase activity, known to induce cell motility by acting as a signal between integrins and actin cytoskeleton. These remodeled matrix events are essential for invasive cell movement and provide a metastasis freeway by which other tumor cells may walk and spread to adjacent tissues [69]. Hypoxia-induced "invasive switch" is also mimicked by Met and autocrine motility factor (AMF) overexpression. Pennacchietti et al. demonstrated that hypoxia synergizes with HGF to affect basal cell morphology and induce cell scattering by transcriptional activation of the MET proto-oncogene. Consistently, increased Met expression sensitizes tumor cells to HGF produced by fibroblasts, promoting thereby the invasive growth toward tissue parenchyma and blood circulation [70]. One of the most important tumor-secreted cytokines, AMF promotes resistance to apoptosis in tumor cells and angiogenesis induction via autocrine and paracrine mechanisms [71].

Hypoxia-selected tumor cells are able to evade the hostile milieu of primary site by promoting angiogenesis and affecting vascular integrity and permeability. Consistently, hypoxia-dependent expression of VEGF, MMP1 and MMP2 is essential to offend the vasculature and promote intravasation. MiR-372/373, upregulated in response to hypoxia through HIF- $1 \alpha$, contribute to increased intravasation by targeting the MMP inhibitory protein RECK, resulting in excessive activation of MMPs [72]. Besides VEGF, MMP1 and MMP2, tumor cells extravasation is promoted by Angiopoietin-like 4 (ANGPTL4), a member of vascular regulators angiopoietin family upregulated in the primary tumor by both TGF $\beta$ and hypoxia [58]. As shown by Padua et al., the expression of ANGPTL4 in cancer cells primes these cells to disrupt vascular endothelial tight junctions and increase the capillary permeability, thereby affecting the transendothelial passage [73].

Recent reports suggested that the metastatic seeding at distant organs is influenced by hypoxia-induced factors released from primary tumor, critical for pre-metastatic niche formation. It has been reported that in breast cancer LOX, secreted by hypoxic tumor cells into the bloodstream, modifies the collagen cross-linking in the lungs and promotes the recruitment of $\mathrm{CD} 11 \mathrm{~b}^{+}$myeloid cells to pre-metastatic sites. By the consequent adhesion to cross-linked matrix, CD11 $\mathrm{b}^{+}$myeloid cells produce MMP-2, which supports collagen remodeling by LOX and thereby increases recruitment and subsequent invasion of bone marrow-derived cells. This cell population is thought to create a favorable environment for the incoming primary tumor cells [69].

Hypoxia in primary tumor may also improve metastatic seeding of tumor cells by heightening chemokine $\mathrm{C}-\mathrm{X}-\mathrm{C}$ motif receptor 4 (CXCR4) expression. Specifically, CXCR4-mediated signal transduction can enable tumor cells to home to secondary organs where its ligand Stromal Derived Factor 1 (SDF1) is highly expressed (e.g., lymph nodes, lungs, liver, or bones). The responsiveness of CXCR4 ${ }^{+}$ cells to SDF-1 gradient is positively affected by several molecules produced during inflammation, specifically fibrinogen, fibronectin, $\mathrm{C} 3 \mathrm{a}$, and hyaluronic acid, suggesting that inflammation affects the spreading of CXCR4 $4^{+}$tumor cells [74].

Similarly to primary tumor, hypoxia response molecules facilitate tumor-stromal interactions in secondary sites to support the metastasis colonies proliferation. However, the role of hypoxia in determining the organ-specific metastasis is still unknown. Microarray profiling revealed that hypoxia promotes the expression of lung-metastasis gene signature, including Connective tissue growth factor, Osteopontin, IL-6 and -8, ANGPTL4, and primes ER breast cancer cells in promoting lung colonization by activating an effective angiogenesis. Since bone marrow vasculature is already fenestrated facilitating the transendothelial passage of tumor cells, hypoxia-induced angiogenesis does not provide an advantage for bone metastasis seeding. Thus, it is not surprising that hypoxia activates a limited percentage of bone-metastasis genes, including CXCR4 and dual specificity phosphatase 1, which functions as a stress-inducible MAPK signaling activator [58,75]. Interestingly, experimental models and human cancers implicated TFG $\beta$ in promoting distal metastasis formation. After seeding the lung parenchyma, $\mathrm{ER}^{-}$breast cancer cells take a proliferative advantage from local TGF $\beta$ through induction of the cell differentiation inhibitor ID1 [76]. As shown by Kakonem et al., in mice inoculated by MDA-MB-231 breast cancer cells, osteolytic bone metastases require the recruitment and activation of osteoclasts. In particular, 
induction of IL-11 and parathyroid hormone-related protein production by TGF $\beta$ promotes differentiation of osteoclast precursors and bone resorption, thereby increasing the osteoblastic expression of Receptor Activator for NF- $\kappa B$ (RANK) ligand [77]. Lastly, Batlle et al. speculated that IL-11, a TGF $\beta$-target gene in stromal cells, confers metastatic initiation capacity to CRC cells via GP130/STAT3 signaling, critical to induce a survival advantage and suppress apoptotic stimuli in metastatic sites [78].

\section{CSCs and vasculature cells crosstalk: a mutual convenience}

Tumor cell growth and nurture require several strategies to supply the oxygen and metabolic demand, all involving new vessels formation and captivation from the surrounding stroma. Tumor neovascularization can occur through (a) sprouting from existing vessels (sprouting angiogenesis), (b) lumen invagination and splitting of vessels (intussusceptive angiogenesis), (c) enfolding of vessels by cancer cells (vessel co-option),(d) simulation of endothelial features by tumor cells (vasculogenic mimicry), (e) formation of lymphatic vessels from pre-existing ones (lymphangigogenesis) and finally (f) endothelial progenitor cells recruitment [79].

Angiogenesis has been defined as a key process for tumor and metastasis formation and CSCs are predicted to be strong promoters of this phenomenon. For instance, Bao et al. demonstrated a profound interplay between CSCs and tumor vasculature. Injection of glioblastoma stem cells (GSCs) $\mathrm{CD} 133^{+}$in the right frontal lobes of athymic nude mice displays strongly angiogenic and hemorrhagic tumors compared to the $\mathrm{CD} 133^{-}$counterpart. The angiogenic advantage of the $\mathrm{CD} 133^{+}$fraction may be supported by a 10-20 fold increase of VEGF secretion. Significantly, conditioned medium from these fractions fosters human endothelial cells migration and tube formation [80]. According to these data, the concomitant presence of CSCs correlates with more angiogenic tumors in terms of enhanced resident endothelial cells function and recruitment of bone marrow-derived endothelial progenitors to the tumor site. VEGF and SDF1 are the main powering determinant of these CSCs properties [81].

On the other hand, it is likely conceivable a possible impact of endothelial cells on CSCs state. A paracrine signaling by endothelial cells may induce CRC cells to gain CSC properties with Notch pathway as the main player of this conversion. Indeed, Jagged-1, a Notch-activating ligand, is released from endothelial cells as a soluble form by ADAM17 proteolitic cleavage and its binding to Notch receptor of adjacent CRC cell triggers the onset of stem-like features. Co-culturing CRC cells either with endothelial cancer cells or with endothelial cell-conditioned medium lead to an increase of the $\mathrm{CD} 133^{+} / \mathrm{ALDH}^{+}$subpopulation compartment and sphere forming capability as well as in vivo tumor growth and spreading [82].

Similarly, as showed by Calabrese et al., it was demonstrated that endothelial-derived factors support self-renewing of brain tumor cells and keep them in an undifferentiated state. These stem-like cells closely interact with $\mathrm{CD}_{3} 4^{+}$capillaries and are strictly dependent on microvasculature density. Co-injection of primary human endothelial cells and CD $133^{+}$medulloblastoma cells accelerates initiation and promotion of brain tumor xenografts by expanding the CSCs pool. Thus, tumor microenvironment orchestrates a vascular niche formation determining the CSCs fate [83].

Furthermore, the presence of 'mosaic' blood vessels in which both endothelial and tumor cells are located into the lumen surface of tumor vessels has long been described [84]. Consistent with these findings, glioblastoma stem cells can be induced to differentiate into endothelial cells and directly contribute to tumor vasculature architecture when injected in immunocompromised mice, as proven by the presence of $C D 34^{+} / \mathrm{CD} 144^{+} /$VEGFR $2^{+}$human-derived endothelial cells [85]. Likewise, vasculogenic mimicry can occur via a multipotent intermediate $\left(\mathrm{CD} 133^{+} / \mathrm{CD} 144^{+}\right)$that can differentiate either into a tumoral or endothelial phenotype [86].

Another related possibility is that, rather than differentiation into endothelial lineage, CSCs generate vascular pericytes that mainly support endothelial cells to maintain vessels function and integrity. It was recently shown that, after GSC differentiation induction, a fraction of $4-11 \%$ cells expressed several pericyte markers such as $\alpha$-SMA, NG2, CD146 and CD248. Significantly, in vivo cell lineage tracing with specific fluorescent reporter confirmed that the majority of pericytes had GSC origin. Of note, selective deletion of GSC-derived pericytes hampered microvessel development and tumor growth. CXCR4 expressing GSCs were recruited toward epithelial cells by an SDF- 1 chemoattractant gradient and then induced to pericytes differentiation upon TGF- $\beta$ release by endothelial cells [87].

\section{Angiogenic pathways orchestrate CSCs survival and motility}

Although CSCs represent a minority of tumor cells population, deregulation of pathways involved in cell self-renewal and motility contributes to cancer conversion and promotion. In addition to well established CSCs radioresistance and chemoresistance mechanisms, an increasing adaptability to antiangiogenic treatment was shown [88]. These cells can elicit resistance and increase their tumorigenic and invasive potential by exploiting an hypoxic microenvironment [89] as well as the activation of an antiapoptotic program [88] (Fig. 3).

Among molecules that regulate tumor angiogenesis, such as plateled-derived growth factor (PDGF), FGF, HGF and TGF- $\alpha / \beta$, VEGFs and their cognate receptors (VEGFRs) are the driving force of angiogenic response due to their specific expression on endothelial and tumoral cells, resulting in multiple signal pathways activation.

VEGF family is represented by five members (VEGFA, VEGFB, VEGFC, VEGFD and placental growth factor [PGF]) coupled with three tyrosine kinase receptors (VEGFR1 [Flt1], VEGFR2 [KDR/Flk1] and VEGFR3 [Flt4]). As a soluble factor, VEGF serum concentration, in preoperative CRC, reflects the stage and correlates with disease progression. Both VEGFs and VEGFR2 are associated with a worse prognosis, tumor spreading and enhanced microvessel density. Particularly, VEGF expression increases during the colonic adenoma-adenocarcinoma pathogenesis conversion and prior to the invasive phenotype switch [90].

VEGFR1 is mostly expressed on endothelial cells, monocytes, macrophages, hematopoietic stem cells and some tumoral cells, including CRC cells [91]. VEGFB and PGF have been identified as its exclusive ligands. VEGFR2 is not restricted to endothelial cells but it is also shared by, for example, colitis-associated colon cancer epithelial cells [92] and GSCs [93]. Furthermore, VEGFR3, the first normal lymphatic endothelium marker [94], together with VEGFC is involved in cancer lymphangiogenesis [95].

VEGFA/VEGFR2 interaction is recognized as a potent proangiogenic stimulus increasing survival, proliferation, migration, and vascular permeability of endothelial cells [96]. Although VEGFA has a higher binding affinity for VEGFR1, VEGFR2 possesses a greater tyrosine kinases activity that governs the activation of MAPkinase, PI3K, Fak and Rac pathways. Interestingly, phosphorylation of p38MAPK, in colon CSCs, protects them from antiangiogenic treatment through the activation of Heat shock protein 27 (Hsp27) [88]. Hypoxic induction of VEGF is not merely dependent on HIF-1 $\alpha$. It was already reported that CRC cells are forced to express VEGF through a K-Ras/PI3K/Rho/ROCK/c-Myc axis. Indeed, a putative Myc-Max binding site was found on VEGF gene promoter [97]. 


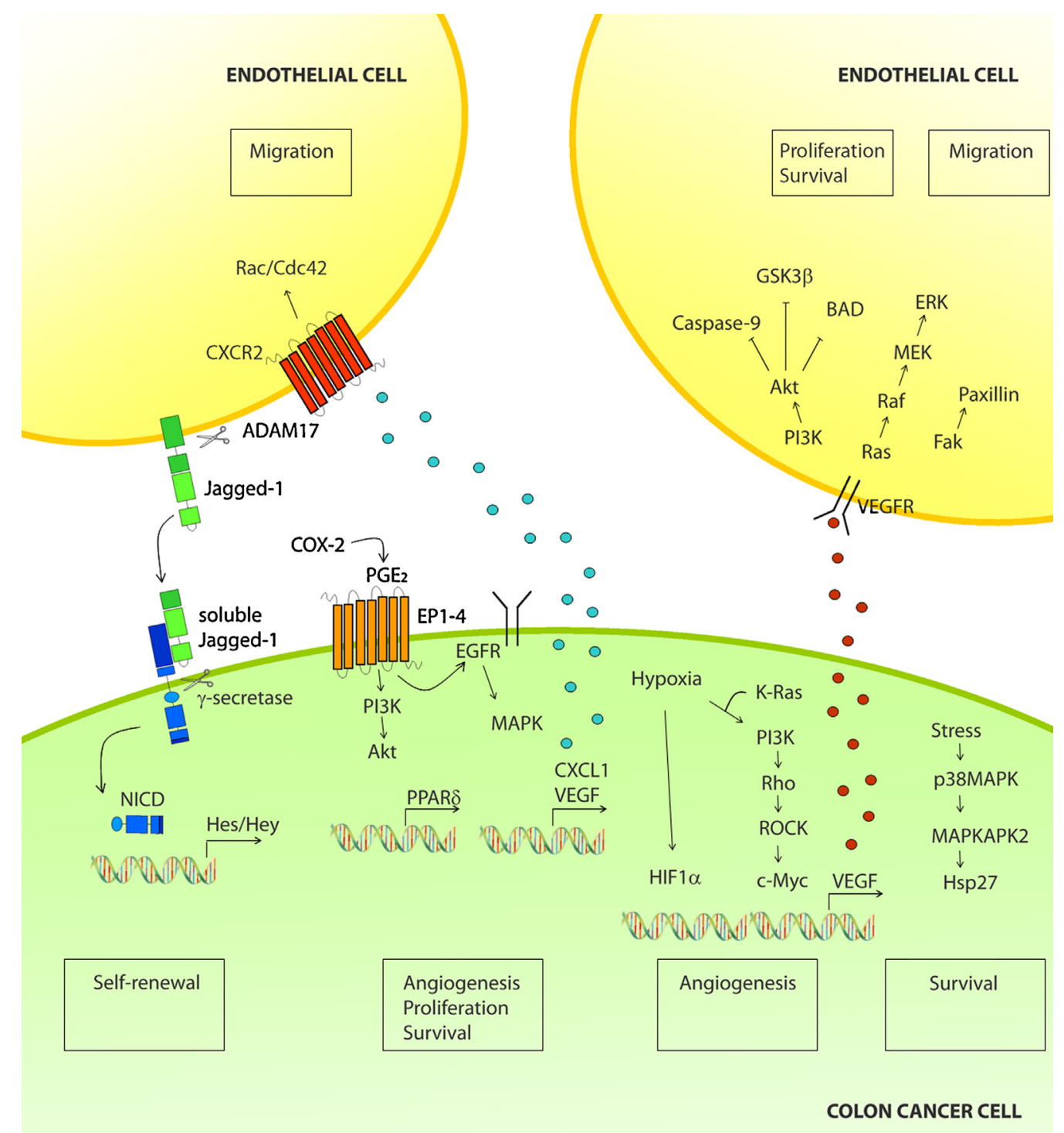

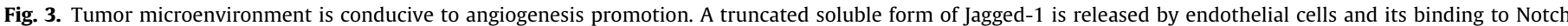

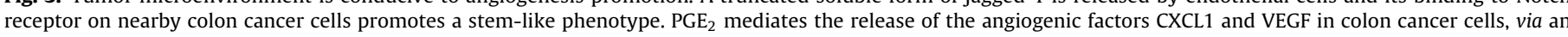

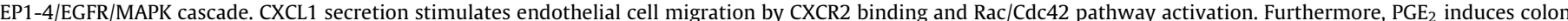

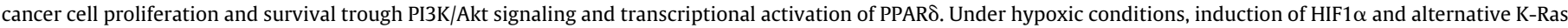

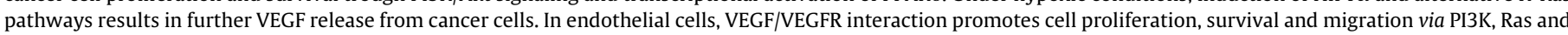

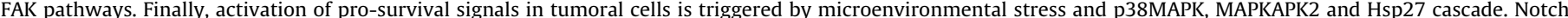

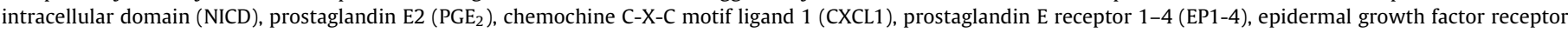

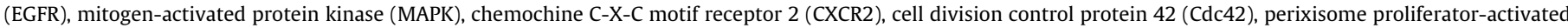
receptor $\delta$ (PPAR $\delta$ ), Rho-associated protein kinase (ROCK), MAP kinase-activated protein kinase 2 (MAPKAPK2), Heat shock protein 27 (Hsp27).

It was extensively observed that Prostaglandin E2 $\left(\mathrm{PGE}_{2}\right)$ is abundantly secreted by both colon cancer cells and stromal cells and promotes the release of the angiogenic factors $\mathrm{C}-\mathrm{X}-\mathrm{C}$ motif ligand 1 (CXCL1) and VEGF through the Prostaglandin E receptor 1-4 (EP1-4)/Epidermal growth factor receptor (EGFR)/MAPK cascade. Tumor-derived CXCL1 stimulates endothelial cell migration and in vivo tumor growth and microvessels density by CXCR2 binding and Rac/Cdc42 pathway activation. Furthermore, $\mathrm{PGE}_{2}$, via PI3K/Akt signaling, enhances transcriptional activation of Perixisome proliferator-activated receptor $\delta$ (PPAR $\delta$ ) required for colorectal adenoma growth $[98,99]$.

The angiogenic properties of VEGF may be amplified when tumoral endothelium is previously destabilized by other growth factors, such as Ang-2. Ang-1, 2 and 4 bind the same endothelial receptor Tie2. While Ang- 1 is expressed by pericytes, smooth muscle cells and tumor cells, Ang-2 is exclusive to endothelial cells. Ang1 preserves vascular integrity by reducing cell-to-cell gaps whereas Ang2 increases pericytes dissociation and vessels destabilization, rendering endothelial cells more receptive to foreign stimuli, for instance, VEGF [100].

A broad spectrum of clinical data reports that activating KRAS mutations could occur up to $50 \%$ of early stages CRC patients [101]. Interaction of Ras with the catalytic subunit p110 of PI3K appears to be extremely relevant to the induction of VEGF gene expression. PI3K phosphorylates Akt, which subsequently inhibits GSK-3 $\beta$ leading to $\beta$-catenin nuclear translocation. Mutated KRAS enhances the stability of $\beta$-catenin and promotes the formation of nuclear $\beta$-catenin/TCF4 complexes [102]. In addition, further evidence of a cooperative interaction between K-Ras and Wnt pathway in CRC lies in the presence of a consensus TCF4 element in the VEGF promoter [103]. At the early onset of colon neoplastic lesion, a crosstalk between Ras and the microenvironment has been described. 
Particularly, RAS oncogene can orchestrate endothelial and inflammatory cells recruitment to the tumor site in an IL-8-dependent manner [104]. On the other hand, as previously mentioned, in wild type KRAS CRC and in presence of an hypoxic microenvironment, VEGF expression is strictly regulated by Akt and c-Src pathways [60].

Entirely conflicting with other Ras oncoprotein features, R-Ras is described as a supporter of tumor vessels normalization by counteracting VEGF angiogenic potential. Tumor vasculature differs from the normal counterpart for the presence of saccular, tortuous and high permeable vessels with fibrin-gel matrix deposition. Pericytes are poorly associated with endothelial cells supported by an irregular basement membrane. Vessel leakiness allows cancer cells to easily penetrate into the bloodstream and thus colonize distant organs. In addition, plasma leakage from vessels, due to an higher interstitial hydrostatic pressure at the tumor site, reduces the delivery of chemotherapeutic agent [105]. However, R-Ras does not affect the oxygen-sensing mechanism of vessel normalization exerted by PHD2 or HIF- $2 \alpha$ under hypoxic condition. Conversely, it facilitates the accumulation of VE-cadherin on cell-to-cell junction, favoring the stabilization of the endothelial barrier. Indeed, it reduces phosphorylation of Ser665 in the cytoplasmic domain of VE-cadherin, suppressing its internalization on endothelial cells. Interestingly, this phenomenon antagonizes VEGF-mediated VEcadherin phosphorylation. Furthermore, R-Ras activity in pericytes increases their interaction with endothelial cells, leading to normal vessels morphogenesis [106].

Based on this observation, antiangiogenic therapies may contribute to the normalization of tumor vasculature architecture and consequently improve their distribution and efficacy [107].

Finally, the BMPs pathway was observed aberrantly regulated in the majority of sporadic CRC and germline mutation on BMP receptors and downstream substrates were detected in juvenile polyposis [108]. Furthermore, BMP signaling has been shown to be essential in human intestinal development and regeneration regulating also the number and the self-renewal state of colonic stem cells [109]. To date, little is known about BMPs role in angiogenesis. Recently, BMP9 was identified as a ligand of the orphan Activin receptor-like Kinase 1 (Alk1) in endothelial cells and the resulting interaction affects several angiogenic steps. BMP9/Alk1 signaling counteracts bFGF-stimulated endothelial cells proliferation and migration as well as VEGF-induced angiogenesis. Indeed, BMP9/Alk1/BMP receptor II (BMPRII) complex abolished VEGF expression through suppression of TGF $\beta / A$ lk5/BMPRII signaling [110]. Certainly, further investigations are needed to identify the underlying mechanism of BMP engagement during angiogenesis promotion.

\section{Therapeutic advances}

Quiescent cells within the stemness niche have been associated with tumor recurrence and relapse after chemotherapy. Targeting the molecular mediators and signaling pathways affecting EMT and tumor progression may provide novel therapeutic strategies to prevent CSCs-dependent distant metastasis formation.

Fighting neovascularization to counteract cancer promotion is a crucial step of the long-standing theory of Folkman [111]. Based on this hypothesis, the first antiangiogenic compound approved by the FDA, in 2004, was Bevacizumab. It is a monoclonal antibody against VEGF recommended in first and second line settings, either with FOLFOX (5-Fluorouracil, Leucovorin and Oxaliplatin) or FOLFIRI (5Fluorouracil, Leucovorin and Irinotecan). As shown by preclinical data, Aflibercept is a VEGFA, VEGFB and Placental growth factor (PIGF) decoy receptor, composed of VEGFR1 and VEGFR2 extracellular domains fused to the constant portion of immunoglobulin gamma chain. In 2012, FDA approved the administration of this compound plus FOLFIRI in patients with metastatic CRC with disease progression after oxaliplatin treatment. Recently, advanced clinical trials validate the efficacy of Regorafenib as a VEGFR $1 / 2 / 3$ and Tie2 tyrosine kinase inhibitor [112].

Despite initial therapeutic benefits in patients with metastatic CRC, classic antiangiogenic strategies failed to improve long-term clinical outcomes [113].

Since new development of tumor vasculature implies several complex signaling, alternative angiogenic or anti-apoptotic mechanism could be devised by cancerous cells [88]. Indeed, it has been recently pointed out, by Lu et al., that glioblastoma multiforme treatment with Bevacizumab developed more invasive tumors, as the blockade of VEGF enhances HGF-induced MET phosphorylation [114]. Another attractive approach takes into account that anti-angiogenic treatments favor a hypoxic microenvironment that gives to CSCs population a metabolic advantage and preserves their self-renewal state [89].

Given that anti-angiogenic drugs may enhance tumor invasiveness by blocking de novo angiogenesis and inducing hypoxia, the development of HIF- $1 \alpha$ targeted therapies may reduce or prevent metastasis [58]. There are several agents that affect directly or indirectly the HIF- $1 \alpha$ expression or activity. The binding of HIF- $1 \alpha$ to the co-activator $\mathrm{p} 300 / \mathrm{CBP}$ has been attenuated by the chetomin, a small molecule that interferes with hypoxia-inducible transcription [115]. In addition, the proteasome inhibitor bortezomib, approved for treatment of patients with multiple myeloma and mantle cell lymphoma, impairs the interaction with the coactivator p300/CBP by inducing the hydroxylation of Asn803 in the C-terminal transactivation domain [116]. By blocking HIF- $1 \alpha$ binding to HRE sequence, a step required for transcription induction, anthracyclines have been reported to significantly reduce the prostate tumor growth and vascularization in a mouse model [117]. The topoisomerase I inhibitor topotecan, cardiac glycoside digoxin and PX-478 have also been implicated in HIF- $1 \alpha$ expression, consistent with their remarkable antitumor activity in a variety of human tumor xenograft models [118]. HIF-1 $\alpha$ protein translation is also inhibited by the chaperone Hsp90, which induces its proteasomal degradation in a VHL-independent manner [119]. Nontoxic prodrugs that generate active species in hypoxic tissue by selective bioreduction have now reached advanced clinical trials. Nitroaromatics, quinones, tertiary amine $\mathrm{N}$-oxides, and transition metals are selectively reduced and activated in the absent of $\mathrm{O}_{2}$ to release or activate toxic effectors to eradicate surrounding hypoxic tumor cells. Similarly, the gene-directed enzyme prodrug therapy uses HRE sequence to improve the expression of reductase enzymes, including $\mathrm{P} 450$ reductase, HSV thymidine kinase and cytosine deaminase, which kill hypoxic tumor cells by converting a prodrug into a cytotoxin [58]. Nevertheless, a robust validation of hypoxia inhibitors in clinical trials is needed to support the hypoxia-targeted therapies. Overall, these findings suggest that advanced compounds need to be developed to selectively target cancer microenvironment.

\section{Conclusions}

The reviewed data emphasize the supporting role of the microenvironment in primary tumor establishment and dissemination to distant sites. The critical event of EMT depends on the complex signals produced by stromal components ensuring the generation of CSCs phenotype with increased proliferative capacity and metastatic potential in hostile milieu. In addition, perivascular, hypoxic and premetastatic niches have been proposed to enhance the resistance of CSCs to therapy. Based on this observation, combination therapies targeting hypoxia and de novo angiogenesis may have enormous therapeutic implications by blocking the successful homing of cancer cells to metastatic sites. Thus, a better 
understanding of cancer microenvironment framework could be a crucial key to improving patient cure.

\section{Conflicts of interest}

None declared.

\section{Acknowledgements}

This study was supported by Grants from AIRC to G. Stassi and M. Todaro. Alice Turdo and Simone Di Franco are Ph.D. students in "International Immunopharmacology Course" at University of Palermo. Special thanks go to D. Di Franco, doctor in informatics, and Di Stefano A.B. for their cooperation in the creation of graphic images.

\section{References}

[1] Jemal A, Bray F, Center MM, Ferlay J, Ward E, Forman D. Global cancer statistics CA. Cancer J Clin 2011;61:69-90.

[2] Janne PA, Mayer RJ. Chemoprevention of colorectal cancer. N Engl J Med 2000;342:1960-8.

[3] Dieter SM, Ball CR, Hoffmann CM, Nowrouzi A, Herbst F, Zavidij O, et al. Distinct types of tumor-initiating cells form human colon cancer tumors and metastases. Cell Stem Cell 2011;9:357-65

[4] Maugeri-Sacca M, Vigneri P, De Maria R. Cancer stem cells and chemosensitivity. Clin Cancer Res 2011;17:4942-7.

[5] Sun Y, Nelson PS. Molecular pathways: involving microenvironment damage responses in cancer therapy resistance. Clin Cancer Res 2012;18:4019-25.

[6] Vogelstein B, Fearon ER, Hamilton SR, Kern SE, Preisinger AC, Leppert M, et al. Genetic alterations during colorectal-tumor development. N Engl J Med 1988;319:525-32.

[7] Fearon ER, Vogelstein B. A genetic model for colorectal tumorigenesis. Cell 1990;61:759-67.

[8] Galiatsatos P, Foulkes WD. Familial adenomatous polyposis. Am J Gastroenterol 2006;101:385-98

[9] Fearnhead NS, Britton MP, Bodmer WF. The ABC of APC. Hum Mol Genet 2001:10:721-33.

[10] Kinzler KW, Vogelstein B. Lessons from hereditary colorectal cancer. Cell 1996;87:159-70.

[11] De Sousa EMF, Wang X, Jansen M, Fessler E, Trinh A, de Rooij LP, et al Poor-prognosis colon cancer is defined by a molecularly distinct subtype and develops from serrated precursor lesions. Nat Med 2013;19:614-8.

[12] Dean M, Fojo T, Bates S. Tumour stem cells and drug resistance. Nat Rev Cancer 2005;5:275-84.

[13] Paget S. The distribution of secondary growths in cancer of the breast 1889. Cancer Metastasis Rev 1989;8:98-101.

[14] Adegboyega PA, Mifflin RC, DiMari JF, Saada JI, Powell DW. Immunohistochemical study of myofibroblasts in normal colonic mucosa, hyperplastic polyps, and adenomatous colorectal polyps. Arch Pathol Lab Med 2002;126:829-36.

[15] Powell DW, Mifflin RC, Valentich JD, Crowe SE, Saada JI, West AB. Myofibroblasts. II. Intestinal subepithelial myofibroblasts. Am J Physiol 1999;277:C183-201.

[16] Vermeulen L, De Sousa EMF, van der Heijden M, Cameron K, de Jong JH, Borovski T, et al. Wnt activity defines colon cancer stem cells and is regulated by the microenvironment. Nat Cell Biol 2010;12:468-76.

[17] He TC, Sparks AB, Rago C, Hermeking H, Zawel L, da Costa LT, et al. Identification of c-MYC as a target of the APC pathway. Science 1998:281:1509-12.

[18] Shtutman M, Zhurinsky J, Simcha I, Albanese C, D’Amico M, Pestell R, et al. The cyclin D1 gene is a target of the beta-catenin/LEF-1 pathway. Proc Natl Acad Sci USA 1999;96:5522-7.

[19] Tetsu O, McCormick F. Beta-catenin regulates expression of cyclin D1 in colon carcinoma cells. Nature 1999;398:422-6.

[20] Gregorieff A, Pinto D, Begthel H, Destree O, Kielman M, Clevers H. Expression pattern of Wnt signaling components in the adult intestine. Gastroenterology 2005;129:626-38.

[21] He XC, Yin T, Grindley JC, Tian Q, Sato T, Tao WA, et al. PTEN-deficient intestinal stem cells initiate intestinal polyposis. Nat Genet 2007;39:189-98.

[22] Persad S, Troussard AA, McPhee TR, Mulholland DJ, Dedhar S. Tumor suppressor PTEN inhibits nuclear accumulation of beta-catenin and T cell/lymphoid enhancer factor 1-mediated transcriptional activation. J Cell Biol 2001:153:1161-74.

[23] Rider CC, Mulloy B. Bone morphogenetic protein and growth differentiation factor cytokine families and their protein antagonists. Biochem J 2010;429:1-12

[24] van Es JH, de Geest N, van de Born M, Clevers H, Hassan BA. Intestinal stem cells lacking the Math1 tumour suppressor are refractory to Notch inhibitors. Nat Commun 2010;1:18.
[25] Hegde GV, Munger CM, Emanuel K, Joshi AD, Greiner TC, Weisenburger $\mathrm{DD}$, et al. Targeting of sonic hedgehog-GLI signaling: a potential strategy to improve therapy for mantle cell lymphoma. Mol Cancer Ther 2008;7: 1450-60.

[26] Thiery JP, Acloque H, Huang RY, Nieto MA. Epithelial-mesenchymal transitions in development and disease. Cell 2009;139:871-90.

[27] Valastyan S, Weinberg RA. Tumor metastasis: molecular insights and evolving paradigms. Cell 2011;147:275-92.

[28] Lee JM, Dedhar S, Kalluri R, Thompson EW. The epithelial-mesenchymal transition: new insights in signaling, development, and disease. J Cell Biol 2006;172:973-81.

[29] Le NH, Franken P, Fodde R. Tumour-stroma interactions in colorectal cancer: converging on beta-catenin activation and cancer stemness. Br J Cancer 2008;98:1886-93.

[30] Gulhati P, Bowen KA, Liu J, Stevens PD, Rychahou PG, Chen M, et al. mTORC1 and $\mathrm{mTORC2}$ regulate EMT, motility, and metastasis of colorectal cancer via RhoA and Rac1 signaling pathways. Cancer Res 2011;71:3246-56.

[31] Moustakas A, Heldin CH. Signaling networks guiding epithelial-mesenchymal transitions during embryogenesis and cancer progression. Cancer Sci 2007;98:1512-20.

[32] Friedl P, Alexander S. Cancer invasion and the microenvironment: plasticity and reciprocity. Cell 2011;147:992-1009.

[33] Friedl P, Wolf K. Proteolytic interstitial cell migration: a five-step process. Cancer Metastasis Rev 2009;28:129-35.

[34] Lammermann T, Sixt M. Mechanical modes of ‘amoeboid' cell migration. Curr Opin Cell Biol 2009;21:636-44.

[35] Wolf K, Mazo I, Leung H, Engelke K, von Andrian UH, Deryugina EI, et al. Compensation mechanism in tumor cell migration: mesenchymalamoeboid transition after blocking of pericellular proteolysis. J Cell Biol 2003;160:267-77

[36] Guilluy C, Garcia-Mata R, Burridge K. Rho protein crosstalk: another social network. Trends Cell Biol 2011:21:718-26.

[37] Bhowmick NA, Ghiassi M, Bakin A, Aakre M, Lundquist CA, Engel ME et al. Transforming growth factor-beta1 mediates epithelial to mesenchymal transdifferentiation through a RhoA-dependent mechanism. Mol Biol Cell 2001;12:27-36

[38] Chan AY, Coniglio SJ, Chuang YY, Michaelson D, Knaus UG, Philips MR, et al Roles of the Rac1 and Rac3 GTPases in human tumor cell invasion. Oncogene 2005:24:7821-9.

[39] Makrodouli E, Oikonomou E, Koc M, Andera L, Sasazuki T, Shirasawa S, et al. BRAF and RAS oncogenes regulate Rho GTPase pathways to mediate migration and invasion properties in human colon cancer cells: a comparative study. Mol Cancer 2011;10:118.

[40] Pani G, Galeotti T, Chiarugi P. Metastasis: cancer cell's escape from oxidative stress. Cancer Metastasis Rev 2010;29:351-78.

[41] Fiaschi T, Marini A, Giannoni E, Taddei ML, Gandellini P, De Donatis A, et al. Reciprocal metabolic reprogramming through lactate shuttle coordinately influences tumor-stroma interplay. Cancer Res 2012;72:5130-40.

[42] Giannoni E, Parri M, Chiarugi P. EMT and oxidative stress: a bidirectional interplay affecting tumor malignancy. Antioxid Redox Signal 2012;16:1248-63.

[43] Grivennikov SI, Greten FR, Karin M. Immunity, inflammation, and cancer. Cell 2010;140:883-99.

[44] Dong R, Wang Q, He XL, Chu YK, Lu JG, Ma OJ. Role of nuclear factor kappa B and reactive oxygen species in the tumor necrosis factor-alphainduced epithelial-mesenchymal transition of MCF-7 cells. Braz J Med Biol Res 2007; 40:1071-8

[45] Kalluri R, Zeisberg M. Fibroblasts in cancer. Nat Rev Cancer 2006;6:392-401

[46] Laberge RM, Awad P, Campisi J, Desprez PY. Epithelial-mesenchymal transition induced by senescent fibroblasts. Cancer Microenviron 2012;5:39-44.

[47] Klimova T, Chandel NS. Mitochondrial complex III regulates hypoxic activation of HIF. Cell Death Differ 2008;15:660-6.

[48] Rhyu DY, Yang Y, Ha H, Lee GT, Song JS, Uh ST, et al. Role of reactive oxygen species in TGF-beta1-induced mitogen-activated protein kinase activation and epithelial-mesenchymal transition in renal tubular epithelial cells. J Am Soc Nephrol 2005; 16:667-75.

[49] Zhang KH, Tian HY, Gao X, Lei WW, Hu Y, Wang DM, et al. Ferritin heavy chainmediated iron homeostasis and subsequent increased reactive oxygen species production are essential for epithelial-mesenchymal transition. Cancer Res 2009;69:5340-8.

[50] Storz P. Reactive oxygen species in tumor progression. Front Biosci 2005;10:1881-96.

[51] Tsuji Y. JunD activates transcription of the human ferritin $\mathrm{H}$ gene through an antioxidant response element during oxidative stress. Oncogene 2005:24:7567-78.

[52] Ishimoto $T$, Nagano O, Yae $T$, Tamada $M$, Motohara $T$, Oshima $H$, et al CD44 variant regulates redox status in cancer cells by stabilizing the xCT subunit of system $\mathrm{xc}(-)$ and thereby promotes tumor growth. Cancer Cell 2011;19:387-400.

[53] Orian-Rousseau V, Chen L, Sleeman JP, Herrlich P, Ponta H. CD44 is required for two consecutive steps in HGF/c-Met signaling. Genes Dev 2002;16:3074-86

[54] Misra S, Hascall VC, De Giovanni C, Markwald RR, Ghatak S. Delivery of CD44 shRNA/nanoparticles within cancer cells: perturbation of hyaluronan/CD44v6 interactions and reduction in adenoma growth in Apc Min/+ MICE. J Biol Chem 2009;284:12432-46.

[55] Jung T, Gross W, Zoller M. CD44v6 coordinates tumor matrix-triggered motility and apoptosis resistance. J Biol Chem 2011;286:15862-74. 
[56] Qu Y, Wang J, Ray PS, Guo H, Huang J, Shin-Sim M, et al. Thioredoxin-like 2 regulates human cancer cell growth and metastasis via redox homeostasis and NF-kappaB signaling. J Clin Invest 2011;121:212-25.

[57] Yae T, Tsuchihashi K, Ishimoto T, Motohara T, Yoshikawa M, Yoshida GJ, et al. Alternative splicing of CD44 mRNA by ESRP1 enhances lung colonization of metastatic cancer cell. Nat Commun 2012;3:883.

[58] Lu X, Kang Y. Hypoxia and hypoxia-inducible factors: master regulators of metastasis. Clin Cancer Res 2010;16:5928-35.

[59] Brahimi-Horn MC, Chiche J, Pouyssegur J. Hypoxia and cancer. J Mol Med (Berl) 2007;85:1301-7.

[60] Zeng M, Kikuchi H, Pino MS, Chung DC. Hypoxia activates the K-ras protooncogene to stimulate angiogenesis and inhibit apoptosis in colon cancer cells. PLoS One 2010;5:e10966.

[61] Heddleston JM, Li Z, McLendon RE, Hjelmeland AB, Rich JN. The hypoxic microenvironment maintains glioblastoma stem cells and promotes reprogramming towards a cancer stem cell phenotype. Cell Cycle 2009;8: 3274-84.

[62] Xue X, Taylor M, Anderson E, Hao C, Qu A, Greenson JK, et al. Hypoxia-inducible factor-2alpha activation promotes colorectal cancer progression by dysregulating iron homeostasis. Cancer Res 2012;72:2285-93.

[63] Cannito S, Novo E, Compagnone A, Valfre di Bonzo L, Busletta C, Zamara E, et al. Redox mechanisms switch on hypoxia-dependent epithelial-mesenchymal transition in cancer cells. Carcinogenesis 2008;29:2267-78.

[64] Yang MH, Wu MZ, Chiou SH, Chen PM, Chang SY, Liu CJ, et al. Direct regulation of TWIST by HIF-1alpha promotes metastasis. Nat Cell Biol 2008;10:295-305.

[65] Higgins DF, Kimura K, Bernhardt WM, Shrimanker N, Akai Y, Hohenstein $\mathrm{B}$, et al. Hypoxia promotes fibrogenesis in vivo via HIF-1 stimulation of epithelial-to-mesenchymal transition. J Clin Invest 2007;117:3810-20.

[66] Peinado H, Del Carmen Iglesias-de la Cruz M, Olmeda D, Csiszar K, Fong $\mathrm{KS}$, Vega $\mathrm{S}$, et al. A molecular role for lysyl oxidase-like 2 enzyme in snail regulation and tumor progression. EMBO J 2005;24:3446-58.

[67] Krishnamachary B, Berg-Dixon S, Kelly B, Agani F, Feldser D, Ferreira G, et al. Regulation of colon carcinoma cell invasion by hypoxia-inducible factor 1 . Cancer Res 2003;63:1138-43.

[68] Hongo K, Tsuno NH, Kawai K, Sasaki K, Kaneko M, Hiyoshi M, et al. Hypoxia enhances colon cancer migration and invasion through promotion of epithelial-mesenchymal transition. J Surg Res 2013;182:75-84.

[69] Erler JT, Bennewith KL, Nicolau M, Dornhofer N, Kong C, Le QT, et al. Lysyl oxidase is essential for hypoxia-induced metastasis. Nature $2006 ; 440$ : 1222-6.

[70] Pennacchietti S, Michieli P, Galluzzo M, Mazzone M, Giordano S, Comoglio PM. Hypoxia promotes invasive growth by transcriptional activation of the met protooncogene. Cancer Cell 2003;3:347-61.

[71] Funasaka T, Raz A. The role of autocrine motility factor in tumor and tumor microenvironment. Cancer Metastasis Rev 2007;26:725-35

[72] Loayza-Puch F, Yoshida Y, Matsuzaki T, Takahashi C, Kitayama H, Noda M. Hypoxia and RAS-signaling pathways converge on, and cooperatively downregulate, the RECK tumor-suppressor protein through microRNAs. Oncogene 2010;29:2638-48.

[73] Padua D, Zhang XH, Wang Q, Nadal C, Gerald WL, Gomis RR, et al. TGFbeta primes breast tumors for lung metastasis seeding through angiopoietin-like 4. Cell 2008;133:66-77.

[74] Kucia M, Ratajczak J, Ratajczak MZ. Bone marrow as a source of circulating CXCR4+ tissue-committed stem cells. Biol Cell 2005;97:133-46.

[75] Keyse SM. Dual-specificity MAP kinase phosphatases (MKPs) and cancer. Cancer Metastasis Rev 2008;27:253-61.

[76] Gupta GP, Perk J, Acharyya S, de Candia P, Mittal V, Todorova-Manova K, et al. ID genes mediate tumor reinitiation during breast cancer lung metastasis. Proc Natl Acad Sci USA 2007;104:19506-11.

[77] Kakonen SM, Selander KS, Chirgwin JM, Yin JJ, Burns S, Rankin WA, et al. Transforming growth factor-beta stimulates parathyroid hormone-related protein and osteolytic metastases via Smad and mitogen-activated protein kinase signaling pathways. J Biol Chem 2002;277:24571-8.

[78] Batlle R, Alba-Castellon L, Loubat-Casanovas J, Armenteros E, Franci C Stanisavljevic J, et al. Snail1 controls TGF-beta responsiveness and differentiation of mesenchymal stem cells. Oncogene 2012;32:3381-9.

[79] Hillen F, Griffioen AW. Tumour vascularization: sprouting angiogenesis and beyond. Cancer Metastasis Rev 2007;26:489-502.

[80] Bao S, Wu Q, Sathornsumetee S, Hao Y, Li Z, Hjelmeland AB, et al. Stem celllike glioma cells promote tumor angiogenesis through vascular endothelial growth factor. Cancer Res 2006;66:7843-8.

[81] Folkins C, Shaked Y, Man S, Tang T, Lee CR, Zhu Z, et al. Glioma tumor stem-like cells promote tumor angiogenesis and vasculogenesis via vascular endothelial growth factor and stromal-derived factor 1. Cancer Res 2009;69: 7243-51.

[82] Lu J, Ye X, Fan F, Xia L, Bhattacharya R, Bellister S, et al. Endothelial cells promote the colorectal cancer stem cell phenotype through a soluble form of Jagged-1. Cancer Cell 2013;23:171-85

[83] Calabrese C, Poppleton H, Kocak M, Hogg TL, Fuller C, Hamner B, et al. A perivascular niche for brain tumor stem cells. Cancer Cell 2007;11:69-82.

[84] Chang YS, di Tomaso E, McDonald DM, Jones R, Jain RK, Munn LL. Mosaic blood vessels in tumors: frequency of cancer cells in contact with flowing blood. Proc Natl Acad Sci USA 2000;97:14608-13.

[85] Ricci-Vitiani L, Pallini R, Biffoni M, Todaro M, Invernici G, Cenci T, et al. Tumour vascularization via endothelial differentiation of glioblastoma stem-like cells. Nature 2010;468:824-8
[86] Wang R, Chadalavada K, Wilshire J, Kowalik U, Hovinga KE, Geber A, et al. Glioblastoma stem-like cells give rise to tumour endothelium. Nature 2010;468:829-33.

[87] Cheng L, Huang Z, Zhou W, Wu Q, Donnola S, Liu JK, et al. Glioblastoma stem cells generate vascular pericytes to support vessel function and tumor growth. Cell 2013;153:139-52.

[88] Lin SP, Lee YT, Yang SH, Miller SA, Chiou SH, Hung MC, et al. Colon cancer stem cells resist antiangiogenesis therapy-induced apoptosis. Cancer Lett 2013;328:226-34.

[89] Conley SJ, Gheordunescu E, Kakarala P, Newman B, Korkaya H, Heath AN, et al. Antiangiogenic agents increase breast cancer stem cells via the generation of tumor hypoxia. Proc Natl Acad Sci USA 2012;109:2784-9.

[90] Wong MP, Cheung N, Yuen ST, Leung SY, Chung LP. Vascular endothelial growth factor is up-regulated in the early pre-malignant stage of colorectal tumour progression. Int J Cancer 1999;81:845-50.

[91] Fan F, Wey JS, McCarty MF, Belcheva A, Liu W, Bauer TW, et al. Expression and function of vascular endothelial growth factor receptor-1 on human colorectal cancer cells. Oncogene 2005;24:2647-53.

[92] Waldner MJ, Wirtz S, Jefremow A, Warntjen M, Neufert C, Atreya R, et al. VEGF receptor signaling links inflammation and tumorigenesis in colitis-associated cancer. J Exp Med 2010;207:2855-68.

[93] Yao X, Ping Y, Liu Y, Chen K, Yoshimura T, Liu M, et al. Vascular endothelial growth factor receptor 2 (VEGFR-2) plays a key role in vasculogenic mimicry formation, neovascularization and tumor initiation by Glioma stem-like cells. PLoS One 2013;8:e57188.

[94] Kaipainen A, Korhonen J, Mustonen T, van Hinsbergh VW, Fang GH, Dumont $\mathrm{D}$, et al. Expression of the fms-like tyrosine kinase 4 gene becomes restricted to lymphatic endothelium during development. Proc Natl Acad Sci USA 1995:92:3566-70.

[95] Skobe M, Hawighorst T, Jackson DG, Prevo R, Janes L, Velasco P, et al. Induction of tumor lymphangiogenesis by VEGF-C promotes breast cancer metastasis. Nat Med 2001:7:192-8.

[96] Hoeben A, Landuyt B, Highley MS, Wildiers H, Van Oosterom AT, De Bruijn EA. Vascular endothelial growth factor and angiogenesis. Pharmacol Rev 2004:56:549-80.

[97] Mizukami Y, Fujiki K, Duerr EM, Gala M, Jo WS, Zhang X, et al. Hypoxic regulation of vascular endothelial growth factor through the induction of phosphatidylinositol 3-kinase/Rho/ROCK and c-Myc. J Biol Chem 2006:281:13957-63.

[98] Wang D, Dubois RN. Eicosanoids and cancer. Nat Rev Cancer 2010;10: $181-93$

[99] Wang D, Wang H, Brown J, Daikoku T, Ning W, Shi Q, et al. CXCL1 induced by prostaglandin E2 promotes angiogenesis in colorectal cancer. J Exp Med 2006;203:941-51.

[100] Saharinen P, Eklund L, Pulkki K, Bono P, Alitalo K. VEGF and angiopoietin signaling in tumor angiogenesis and metastasis. Trends Mol Med 2011;17:347-62.

[101] McLellan EA, Owen RA, Stepniewska KA, Sheffield JP, Lemoine NR. High frequency of K-ras mutations in sporadic colorectal adenomas. Gut 1993;34:392-6.

[102] Li J, Mizukami Y, Zhang X, Jo WS, Chung DC. Oncogenic K-ras stimulates Wnt signaling in colon cancer through inhibition of GSK-3beta. Gastroenterology 2005; 128:1907-18.

[103] Zhang X, Gaspard JP, Chung DC. Regulation of vascular endothelial growth factor by the Wnt and K-ras pathways in colonic neoplasia. Cancer Res 2001;61:6050-4.

[104] Sparmann A, Bar-Sagi D. Ras-induced interleukin-8 expression plays a critical role in tumor growth and angiogenesis. Cancer Cell 2004;6:44758.

[105] Jain RK. Normalization of tumor vasculature: an emerging concept in antiangiogenic therapy. Science 2005;307:58-62.

[106] Sawada J, Urakami T, Li F, Urakami A, Zhu W, Fukuda M, et al. Small GTPase R-Ras regulates integrity and functionality of tumor blood vessels. Cancer Cell 2012;22:235-49.

[107] Carmeliet P, Jain RK. Molecular mechanisms and clinical applications of angiogenesis. Nature 2011;473:298-307.

[108] Howe JR, Bair JL, Sayed MG, Anderson ME, Mitros FA, Petersen GM, et al. Germline mutations of the gene encoding bone morphogenetic protein receptor $1 \mathrm{~A}$ in juvenile polyposis. Nat Genet 2001;28:184-7.

[109] He XC, Zhang J, Tong WG, Tawfik O, Ross J, Scoville DH, et al. BMP signaling inhibits intestinal stem cell self-renewal through suppression of Wnt-betacatenin signaling. Nat Genet 2004;36:1117-21.

[110] Shao ES, Lin L, Yao Y, Bostrom KI. Expression of vascular endothelial growth factor is coordinately regulated by the activin-like kinase receptors 1 and 5 in endothelial cells. Blood 2009;114:2197-206.

[111] Folkman J. Tumor angiogenesis: therapeutic implications. N Engl J Med 1971:285:1182-6.

[112] Sun W. Angiogenesis in metastatic colorectal cancer and the benefits of targeted therapy. J Hematol Oncol 2012;5:63

[113] Saltz LB, Clarke S, Diaz-Rubio E, Scheithauer W, Figer A, Wong R, et al. Bevacizumab in combination with oxaliplatin-based chemotherapy as first-line therapy in metastatic colorectal cancer: a randomized phase III study. J Clin Oncol 2008;26:2013-9.

[114] Lu KV, Chang JP, Parachoniak CA, Pandika MM, Aghi MK, Meyronet D, et al. VEGF inhibits tumor cell invasion and mesenchymal transition through a MET/VEGFR2 complex. Cancer Cell 2012;22:21-35. 
[115] Kung AL, Zabludoff SD, France DS, Freedman SJ, Tanner EA, Vieira A, et al. Small molecule blockade of transcriptional coactivation of the hypoxia-inducible factor pathway. Cancer Cell 2004;6:33-43.

[116] Kaluz S, Kaluzova M, Stanbridge EJ. Proteasomal inhibition attenuates transcriptional activity of hypoxia-inducible factor 1 (HIF-1) via specific effect on the HIF-1alpha C-terminal activation domain. Mol Cell Biol 2006;26: 5895-907.

[117] Lee K, Qian DZ, Rey S, Wei H, Liu JO, Semenza GL. Anthracycline chemotherapy inhibits HIF-1 transcriptional activity and tumor-induced mobilization of circulating angiogenic cells. Proc Natl Acad Sci USA 2009;106: 2353-8.

[118] Isaacs JS, Jung YJ, Mimnaugh EG, Martinez A, Cuttitta F, Neckers LM. Hsp90 regulates a von Hippel Lindau-independent hypoxia-inducible factor1 alpha-degradative pathway. J Biol Chem 2002;277:29936-44.

[119] Onnis B, Rapisarda A, Melillo G. Development of HIF-1 inhibitors for cancer therapy. J Cell Mol Med 2009;13:2780-6. 